\title{
Produção de lipase utilizando manipueira como fonte alternativa de carbono
}

Lipase production using cassava water as alternative source of carbon

\author{
M. V. de Jesus ${ }^{1}$; T. S. de Oliveira²; R. D. M. Ferreira' ${ }^{1}$ A. M. de Lima ${ }^{3}$; J. R. da S. \\ Rodrigues $^{1}$; C. F. Silva ${ }^{3}$; R. R. de Souza ${ }^{3 *}$
}

${ }^{1}$ Departamento de Engenharia Química, Laboratório de Biotecnologia Ambiental, Universidade Federal de Sergipe, 49100-000, São Cristóvão-Sergipe, Brasil. Tel. +55 (79) 2105-6677

${ }^{2}$ Programa de Pós-Graduação em Engenharia Química, Laboratório de Biotecnologia Ambiental (LABAM), Universidade Federal de Sergipe, 49100-000, São Cristóvão-Sergipe, Brasil. Tel. +55 (79) 2105-6549.

${ }^{3}$ Programa de Pós-Graduação em Engenharia Química, Laboratório de Biotecnologia Ambiental (LABAM), Departamento de Engenharia Química//Laboratório de Bioquímica Industrial/ Universidade Federal de Sergipe, 49100-000, São Cristóvão-Sergipe, Brasil. Tel. +55 (79) 2105-6677

*rrsouza@ufs.br

(Recebido em 15 de março de 2016; aceito em 22 de abril de 2016)

As lipases são enzimas capazes de realizar a hidrólise de ácidos graxos, reação que é muito importante nas indústrias e mais especificamente para a produção de biodiesel. Pode ser produzida por animais, vegetais e micróbios, sendo a última forma a mais vantajosa. A sua produção em laboratório tem sido muito repetida e mostra resultados muito satisfatórios. Uma infinidade de maneiras de cultivo desta enzima é desenvolvida, variando os tipos de micro-organismos produtores, tipos de substrato, e processos de fermentação. Dentre as bactérias capazes de produzir lipase, o Bacillus subtilis se destaca notadamente nas pesquisas publicadas por se desenvolver e produzir a enzima em condições adversas. Muito frequentemente, resíduos da indústria agrícola são utilizados como meio de cultura desses micróbios, seja para baixar os custos de produção, seja para dar utilidade a tais rejeitos. Neste trabalho, a manipueira, resíduo líquido do processamento da mandioca, foi utilizada como fonte alternativa de carbono para a produção da lipase e seus resultados comparados com diferentes meios de fermentação sendo comprovada a sua eficiência na produção da enzima.

Palavras-chave: lipase, Bacillus subtilis, manipueira

Lipases are enzymes capable of carrying out the hydrolysis of fatty acid, a reaction which is very important in industry and more specifically for the production of biodiesel. Can be produced by animals, plants and microbes, the latter being the most advantageous way. Its production in the laboratory has been much repeated and shows very satisfactory results. A multitude of ways of cultivation of this enzyme is developed, varying the types of micro-organisms producers, types of substrate and fermentation processes. Among the bacteria capable of producing lipase, Bacillus subtilis stands out markedly in published research by developing and producing the enzyme in adverse conditions. Very often, the agricultural industry wastes are used as culture medium of these microbes, or to reduce production costs, it is useful to provide such wastes. In this work, liquid waste processing of cassava, was used as an alternative source of carbon for the production of lipase and its results compared with different fermentation media being proven its efficiency in the production of the enzyme.

Keywords: lipase, Bacillus subtilis, cassava water.

\section{INTRODUÇÃO}

As lipases são enzimas hidrolíticas que entre outras utilidades, catalisam a conversão de triacilgliceróis (TAG’s), fornecendo ácidos graxos livres e glicerol [1].

A reação de hidrólise realizada pela lipase consiste no ataque á ligação éster do TAG (triacilglicerol) para produzir glicerol e ácidos graxos, na presença de água. O tipo e a posição estereoespecífica do resíduo de ácido graxo estão relacionados com a alta especificidade das lipases, o que propicia um grande número de aplicações [2]. 
Segundo Pastore et al [3], a atividade lipolítica é muito aumentada quando situada na interface polar/apolar e apresentam maior afinidade por ácidos graxos de cadeia longa. Com a técnica da difração de raios-X, foi possível obter a estrutura tridimensional de algumas lipases sendo possível deste modo, compreender melhor os fatores que determinam sua região especificidade, enantioseletividade e o mecanismo de ação. Fatores esses, que as tornam uma das classes de enzimas mais atraentes e utilizadas em aplicações biotecnológicas específicas.

As lipases constituem um grupo de produtos biológicos de extrema importância e necessidade para a vida humana, sendo amplamente encontradas na natureza. São obtidas a partir de fonte animal, vegetal e microbiana [4], porém somente as lipases microbianas são comercialmente utilizadas, por poderem ser manipuladas. Pertencem a um importante grupo de enzimas devido à versatilidade de suas propriedades e fácil produção em massa, além de oferecer um amplo espectro de características físico-químicas [5].

Depois das proteases e das amilases, as lipases são consideradas o terceiro grupo mais importante e representativo do mercado das enzimas. Contudo, o seu uso é caracterizado pelos elevados custos de produção [6]. Esse fato faz com que a procura por meios menos custosos para a sua produção sejam pesquisados, bem como o uso de variados micro-organismos produtores; diferentes maneiras de conduzir o processo e diferentes meio de cultura dos micro-organismos.

A possível substituição dos meios de fermentação sintéticos por meios naturais igualmente eficazes reduziria os custos operacionais, ao tempo em que possibilitaria uma maior popularização da modalidade. Desta forma os resíduos agroindustriais, pelo baixo custo e grande disponibilidade, têm se mostrado uma alternativa perfeita, casando economia e sustentabilidade.

No contexto da realidade do estado de Sergipe, e tendo conhecimento da grande variedade de rejeitos da agricultura, podemos citar como destaque a manipueira, que é um dos resíduos gerados pelo processamento da mandioca, tubérculo de grande produção no estado.

A manipueira é um líquido leitoso extraído após a prensagem da mandioca que por conter cianeto de hidrogênio, torna-se venenoso e, por esse fato, é descartado na maioria das vezes de forma concentrada e em grande quantidade a céu aberto ou em cursos d'água, gerando danos ao meio ambiente.Segundo Nasu [7], a composição química da manipueira varia de acordo com a variedade da mandioca e das condições edafoclimáticas da região do plantio. De maneira geral, um terço do amido da mandioca permanece na manipueira. Então, encontram-se presentes na solução fósforo, potássio, cálcio e magnésio, além de micronutrientes essenciais para a manutenção da nutrição de micro-organismos, plantas e alguns animais. A Tabela 1 mostra a composição média da manipueira, citada por um trabalho na literatura.

Tabela 1: Composição química da manipueira

\begin{tabular}{|c|c|}
\hline Componente & Aragão e Ponte [8] \\
\hline Nitrogênio (N) & 425,5 \\
\hline Fósforo (P) & 259,5 \\
\hline Potássio (K) & 1863,5 \\
\hline Cálcio $(\mathrm{Ca})$ & 227,5 \\
\hline Magnésio (Mg) & 405,0 \\
\hline Enxofre (S) & 195,0 \\
\hline Ferro $(\mathrm{Fe})$ & 15,3 \\
\hline Zinco (Zn) & 4,2 \\
\hline Cobre $(\mathrm{Cu})$ & 11,5 \\
\hline Manganês (Mn) & 3,7 \\
\hline Cianeto total $(\mathrm{CN})$ & 604,0 \\
\hline
\end{tabular}


Consoante a esta linha de raciocínio, neste trabalho a manipueira (resíduo líquido da mandioca, Manihot esculenta Crantz) foi testada como meio de fermentação submersa para avaliar a produção da enzima lipase pela bactéria Bacillus subtilis. Concomitantemente, o mesmo experimento foi produzido trocando a manipueira por solução de amido e um meio sintético para comparar a eficiência de produção de lipase durante 72 horas, variando também o pH e a agitação em cada meio.

\section{METODOLOGIA}

\subsection{Preparo do Substrato Manipueira}

A manipueira utilizada nos experimentos foi coletada numa fábrica de farinha localizada no município de Itaporanga D'Ajuda, distante $26 \mathrm{~km}$ da capital do Estado de Sergipe, Aracaju. O preparo do substrato seguiu a orientação de Barros et al [9], onde a manipueira foi aquecida até à ebulição, resfriada, centrifugada a $3400 \mathrm{rpm}$ durante $20 \mathrm{~min}$. As Figuras 1 e 2 apresentam a manipueira em sua forma bruta e tratada, respectivamente.

Este processo teve como objetivo a solubilização do amido, a remoção de sólidos em suspensão, e a eliminação de cianeto de hidrogênio. Após este processo, o líquido resultante era chamado de manipueira tratada. Para as experiências, $50 \mathrm{~mL}$ deste meio foram esterilizados em autoclave a $121^{\circ} \mathrm{C}$ durante $20 \mathrm{~min}$.

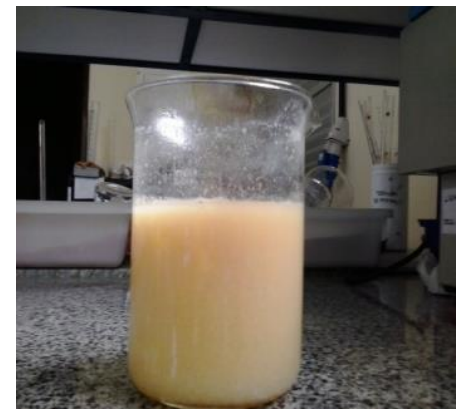

Figura 1: Manipueira bruta

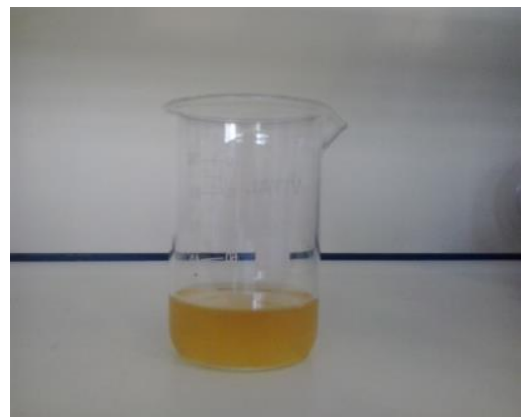

Figura 2: Manipueira tratada

\subsection{Substrato Solução de Amido $1 \%$}

Leonel e Cereda [10] relatam a presença de 5,71\% de amido na manipueira, o que nutriu a curiosidade em testar uma solução de amido $1 \%$ como substrato na produção da lipase por Bacillus subtilis e comparar os seus resultados com os valores obtidos utilizando manipueira tratada e um meio sintético, como substrato na produção da lipase.

\subsection{Micro-organismo e Preparo dos Meios Fermentativos}

O micro-organismo utilizado foi o Bacillus subtilis, pertencente ao banco de cepas do LABAM. Ele foi isolado através do método da semeadura por esgotamento em placas de Petri contendo meio ágar Nutriente. Os isolados obtidos foram mantidos resfriados em tubos inclinados de ágar.

Um ciclo de crescimento da cultura foi feito contendo $150 \mathrm{~mL}$ de caldo nutritivo e mantidos durante $24 \mathrm{~h}$ em shaker a uma velocidade de $150 \mathrm{rpm}$. Este caldo utilizado para experiências continha ( $\mathrm{g} / \mathrm{L}$ de água destilada): extrato de carne 1,0; extrato de levedura 2,0; extrato de peptona 5,0 e cloreto de sódio 5,0 .

O meio sintético utilizado como substrato foi preparado conforme combinação de nutrientes utilizados para o caldo nutritivo citado acima. 


\subsection{Fermentação}

Uma alíquota de 3,0 mL de inóculo foi adicionada a cada Erlenmeyer contendo $50 \mathrm{~mL}$ de manipueira tratada, meio sintético e solução de amido. A fermentação foi realizada de acordo com os seguintes parâmetros: temperatura de $30^{\circ} \mathrm{C}$, agitação a 120,150 e $180 \mathrm{rpm}, \mathrm{pH} 5,7$ e 9 durante $72 \mathrm{~h}$. Amostras foram obtidas em intervalos de 24 horas para determinação da atividade enzimática.

\subsection{Medição da Atividade Enzimática}

A atividade enzimática pode ser determinada direta ou indiretamente, pelo consumo do substrato ou pela formação dos produtos sendo assim, a atividade lipolítica foi determinada pela liberação de ácidos graxos [11].

\subsection{Preparo do Extrato Enzimático}

Cada amostra foi centrifugada a $3400 \mathrm{rpm}$ em um tubo de centrífuga por $8 \mathrm{~min}$ para remover as células. O sobrenadante, denominado extrato enzimático foi usado para determinar a atividade enzimática.

\subsection{Quantificação da Atividade Lipolítica}

De acordo com Barros et al [9], a atividade lipolítica é geralmente determinada pela liberação dos ácidos graxos produzidos pela hidrólise, que podem ser quantificados por métodos colorimétricos, fluorimétricos, titulométricos, turbidimétricos.

Neste ensaio, $1 \mathrm{~mL}$ de extrato foi adicionado em frascos contendo $4 \mathrm{~mL}$ de tampão fosfato 0,2 M; $1 \mathrm{~mL}$ de $\mathrm{CaCl}_{2} 110 \mathrm{~mm}$, e $5 \mathrm{~mL}$ de emulsão de $25 \%$ (v/v) azeite em goma arábica $7 \%$ (p/v). Os frascos foram incubados a $37{ }^{\circ} \mathrm{C}$ e $180 \mathrm{rpm}$ durante 20 minutos. Após a incubação, a reação foi interrompida pela adição de $15 \mathrm{~mL}$ de acetona/etanol (1:1), e foi mantido num agitador por mais 5 minutos. A amostra em branco foi obtida de um modo semelhante como as amostras de extrato, diferindo apenas pela utilização de água destilada em vez do extrato.

Os ácidos graxos liberados pela hidrólise de triacilglicerol foram titulados com $\mathrm{NaOH}$ a 0,05 $\mathrm{M}$ e $20 \mu \mathrm{L}$ de fenolftaleína. Uma unidade de lipase (U) foi definida como a quantidade de enzima capaz de libertar um $\mu$ mol de ácido graxo por minuto $\left(\mu \mathrm{mol} \times \mathrm{min}^{-1}\right)$ sob as condições acima descritas.

\section{RESULTADOS E DISCUSSÃO}

\subsection{Produção da Enzima}

Em consonância com os trabalhos de Barros [12] e [8], a produção da enzima foi detectada com a titulação com NaOH 0,05 M. O consumo do hidróxido de sódio evidenciou a presença do ácido graxo produzido mediante ação de hidrólise da enzima lipase. A lipase foi produzida em todas as condições previstas no planejamento experimental e são mostradas na Figura 3.

Fazendo uma análise da Figura 3, verificamos que a máxima atividade foi atingida com 48 horas de fermentação, consequentemente seria o melhor momento para se parar o processo se este fosse o objetivo principal, entretanto, tínhamos como foco a avaliação da manipueira como fonte alternativa de carbono, logo o processo ficou por maior tempo para comparar este com os demais meios.

Comparando os meios verificamos que o meio sintético apresentou melhor desempenho em termo de atividade, sendo seguido pela manipueira e depois o amido puro. Neste caso destacamos que o meio sintético possui indutores que propicia a produção da lipase com atividade, já a manipueira, um efluente bruto, mostrou um bom desempenho quando comparado com o amido puro, assim, o efluente deve conter componentes que ajudam na produção da lipase sendo um bom indicativo da possibilidade deste como substrato na produção de lipase. 


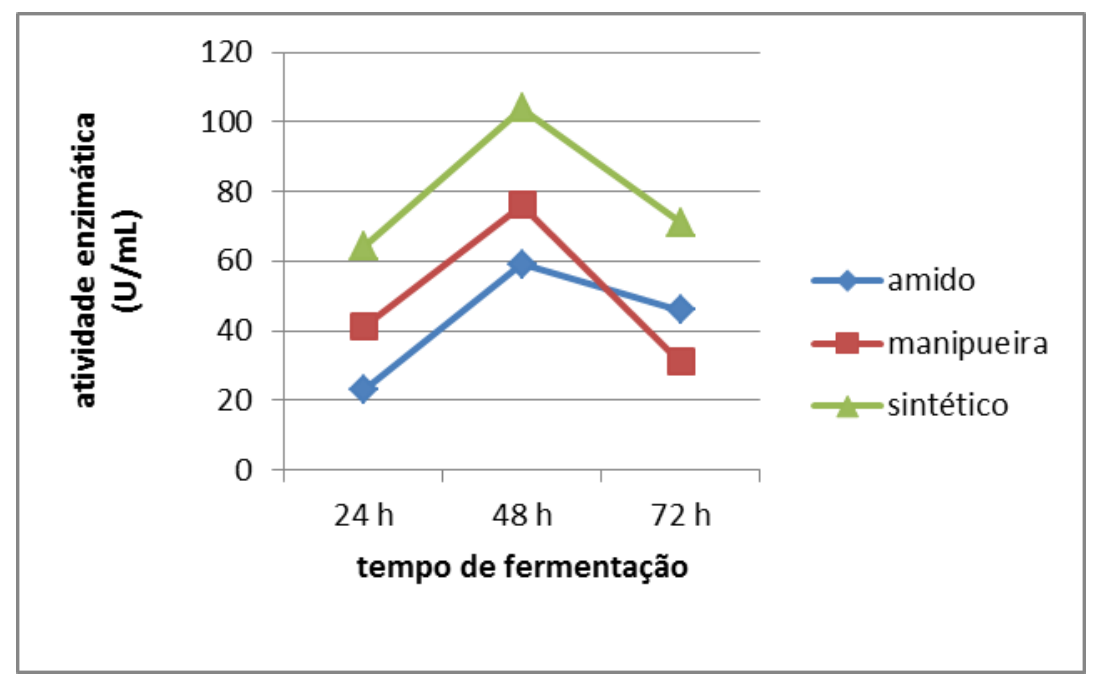

Figura 3: Máxima produção enzimática para cada meio

Nas condições preparadas para o experimento utilizando manipueira como meio de fermentação, houve produção satisfatória da lipase e sua atividade foi detectada em todas as variações de $\mathrm{pH}$ e de rotação, ao longo de 72 horas de incubação.

$\mathrm{O}$ efeito produzido pelo tempo de fermentação quer dizer que com o aumento das horas de fermentação, há uma maior produção de enzima dentro do intervalo estudado. Porém, esse aumento é limitado, sendo que em torno das $72 \mathrm{~h}$ ocorre um decréscimo enzimático. Esse fato pode ser explicado pela grande demanda de nutrientes pelos Bacillus subtilis após 48 horas de fermentação, onde meio manipueira já não fornece quantidade satisfatória destes nutrientes, assim ocorre diminuição da capacidade de se reproduzirem entre si, consequentemente resultando na queda da produção enzimática. Em termos da agitação (rpm), que fornece oxigênio para os produtores da lipase, a produção variou pouco quando comparada à variação mediante tempo de fermentação.

Variando o pH do tampão utilizado nos experimentos com a manipueira, a máxima produção da enzima foi detectada para o $\mathrm{pH} \mathrm{7,} \mathrm{assim} \mathrm{como} \mathrm{encontrado} \mathrm{em} \mathrm{diversos} \mathrm{trabalhos} \mathrm{na} \mathrm{literatura}$ [13]. Percebe-se também que a produção de lipase com pH 9 é equiparável ao $\mathrm{pH}$ neutro, entretanto em pH ácido a lipase não é produzida em quantidade satisfatória. A Tabela 2 mostra com detalhe os resultados encontrados para este ensaio.

Tabela 2: Atividade enzimática da lipase tendo como substrato a manipueira em diferentes pH e com agitação de $150 \mathrm{rpm}$.

\begin{tabular}{c|c|c|c}
\hline Tempo (h) & pH 5,0 & $\mathbf{p H ~ 7 , 0}$ & $\mathbf{p H ~ 9 , 0}$ \\
\hline 24 & 15 & 53 & 50 \\
\hline 48 & 40 & 62 & 46 \\
\hline 72 & 37 & 51 & 37 \\
\hline
\end{tabular}

A produção de lipase em amido foi notada em todos os experimentos com este meio de fermentação e sua atividade quando comparada com os demais meios testados, revelou-se menor, como já visto na Figura 3.

O uso do meio sintético neste trabalho serviu de comparação, visto que a produção em um meio padronizado e controlado é mais provável do que em meios de composição variável, assim como ocorreu.

\subsection{Efeito do pH na Atividade Lipolítica}

A literatura indica que o $\mathrm{pH}$ neutro é definido como sendo ótimo para atividade lipolítica, o que pode ser verificado nos trabalhos de Fadiloglu e Soylemez [14] e Benjamin e Pandey [15]. 
Nas condições estudadas, a lipase de Bacillus subtilis apresentou maior atividade com o pH 7 para qualquer um dos meios, como pode ser observado na Figura 4.

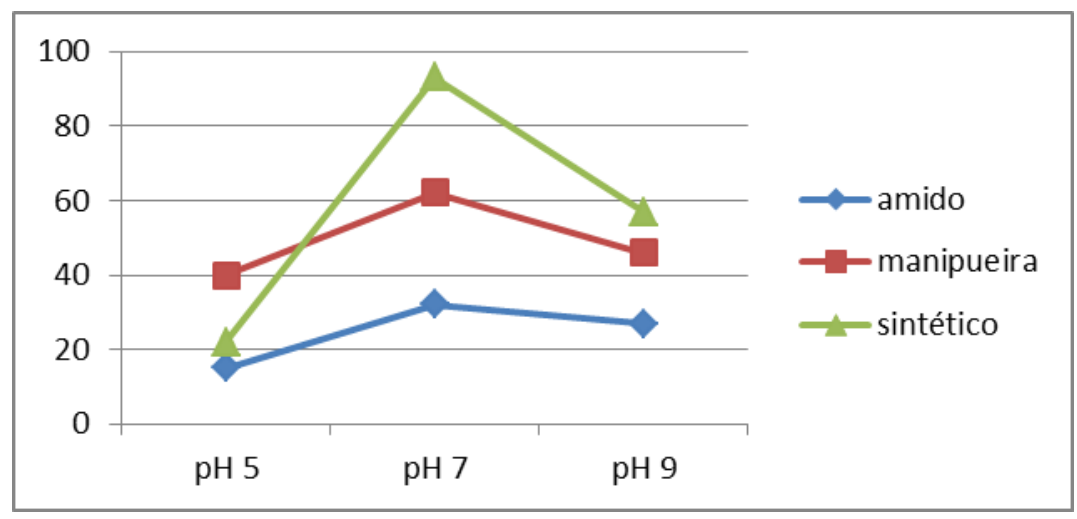

Figura 4: Atividade enzimática de cada meio com variações no $\mathrm{pH}$

Os resultados encontrados mostram que a manipueira apresenta potencial favorável tanto no desenvolvimento do micro-organismo Bacillus subtilis, quanto na produção da enzima lipase.

A manipueira apresentou valores de atividade enzimática significativa, quando comparados ao mesmo fator no meio sintético e na solução de amido, fato que pode ser atribuído á complexa composição química do rejeito agroindustrial utilizado, que reúne vários micro e macro nutrientes necessários á nutrição do micro-organismo, proporcionando dessa forma condições favoráveis para o desenvolvimento da bactéria.

Diferentes resultados para a produção da lipase podem também ser encontrados, podendo ser relacionados a alguns fatores como, por exemplo, a origem do micro-organismo, o meio utilizado, o processo escolhido para condução da fermentação, o tempo de incubação, a temperatura, bem como o método utilizado nos experimentos e substrato utilizado para a medida de atividade, tornando, muitas vezes, inviável a comparação com outros estudos.

\section{CONCLUSÃO}

O Bacillus subtilis foi capaz de produzir a enzima lipase por meio de fermentação submersa utilizando como fonte de carbono, a manipueira tratada, não sendo necessária a adição de indutores enzimáticos, o que evidencia o grande potencial da manipueira quando comparada com os outros meios, amido $1 \%$ e sintético.

A máxima atividade lipolítica na manipueira foi identificada no tempo de 48 horas de fermentação sob condições de pH 7 e agitação de 150 rpm.

Por fim, quando comparada à produção enzimática nos três meios testados: amido, manipueira e meio sintético, percebe-se que a maior produção foi obtida no meio sintético, seguido pela manipueira e a solução de amido $1 \%$.

\section{AGRADECIMENTOS}

Os autores agradecem aos órgãos financiadores FAPITEC, PETROBRAS, CAPES, CNPq e UFS pelo apoio financeiro através de bolsas e financiamento de projetos.

\section{REFERÊNCIAS BIBLIOGRÁFICAs}

1. Mesias JM, Costa BZ, Lima VMGL, Giese EC, Dekker RF, Barbo AM. Microbial lipases: production, properties and biotechnological applications. Semina (Londrina) 2011; 32(2):213-34, doi: 10.5433/1679-0375.

2. Dalla-Vecchia R, Nascimento M, Soldi, V. Aplicações sintéticas de lípase imobilizadas em polímeros. Quím. Nova 2004 Jul/Ago;27(4):623-630, httplldx.doi.org/10.1590/S0100-40422004000400017 
3. Pastore GM, Costa VSR, Koblitz MGB. Purificação parcial e caracterização bioquímica de lipase extracelular produzida por nova linhagem de Rhizopus sp. Ciênc. Tecnol. Aliment. 2003 Ago; 23(2):135-140, httplldx.doi.org/10.1590/S0100-20612003000200006

4. Castro HF, Mendes AA, Santos JC, Aguiar CL. Modificação de óleos e gorduras por biotransformação. Quím. Nova 2004 Jan/Fev:27(1):146-56, httplldx.doi.org/10.1590/S0100-40422004000100025

5. Manfio GP, Lemos MF. Diversidade Microbiana e desenvolvimento sustentável. Microrganismos e aplicações industriais: Actinomicetos na indústria [workshop sobre biodiversidade: perspectivas e oportunidades tecnológicas]. Campinas (SP): Universidade Estadual de Campinas; 1996.

6. Paques FW, Macedo GA. Lipases de látex vegetais: propriedades e aplicações industriais. Quím. Nova $2006 \mathrm{Jan} / \mathrm{Fev}: 29(1): 93-9$, httplldx.doi.org/10.1590/S0100-40422006000100018

7. Nasu EGC. Composição química da manipueira e sua potencialidade no controle de Meloidogyne incógnita em tomateiro no oeste do Paraná. [Dissertação]. Marechal Cândido Rondon (PR): Universidade Estadual do Oeste do Paraná; 2008.

8. Aragão ML, Ponte JJ. O uso da manipueira -extrato líquido das raízes da mandioca- como adubo foliar. Ciênc. Agron. 1995: 46(1-2): 45-8.

9. Barros FFC, Simiqueli APR, Andrade CJ, Pastore G.M. Production of Enzymes from Agroindustrial Wastes by Biosurfactant-Producing Strains of Bacillus subtilis. Biotechnol. Res. Int. 2013:2013, http://dx.doi.org/10.1155/2013/103960

10. Leonel M, Cereda MP. Manipueira como substrato na biossíntese de ácido cítrico por Aspergillus niger. Sci. Agric. 1995 Mai./Ago; 52 (2) http://dx.doi.org/10.1590/S0103-90161995000200016

11. Gonçalves FAG. Produção de lipase extracelular por leveduras de cultivo submerso. [Dissertação] (Mestrado em Ciência de Alimentos) - Faculdade de Farmácia, Universidade Federal de Minas Gerais, Belo Horizonte, 2007, $67 \mathrm{f}$.

12. Barros FFC, Ponezi AN, Pastore GM. Production of biosurfactant by Bacillus subtilis LB5a on a pilot scale using cassava wastewater as substrate. Journ of Ind Microb and Biotech 2008 Jul; 35( 9): 10711078, DOI 10.1007/s10295-008-0385-y

13. Feitosa IC, Barbosa JM, Orellana SC, Lima AS, Soares CMF. Produção de lipase por meio de microrganismos isolados de solos com histórico de contato com petróleo. Acta sci technol. 2010; 32 (1): 27-31, DOI: 10.4025/actascitechnol.v32i1.7550.

14. Fadiloglu S, Soylemez Z. Kinetics of lipase catalyzed hydrolysis of olive oil. Food Res Int 1997 Apr/May; 30 (3-4) :171-175, doi:10.1016/S0963-9969(97)00022-7

15. Benjamin S, Pandey A. Isolation and characterization of three distinct forms of lipases from Candida rugosa produced in solid state fermentation. Braz Arch of Biol and Technol. 2001 Jun; 43(5): 453-460, http://dx.doi.org/10.1590/S1516-89132001000200016 